\title{
At a Loss for Words: Televisual Liveness and Corporeal Interruption
}

\author{
Alla Gadassik ${ }^{1}$
}

\section{Introduction}

In the closing days of 2004, the New York Times published a list of "TV's Best Live Moments" from the preceding year. ${ }^{2}$ By the night of its release, the list already seemed outdated, as television networks scrambled to bring viewers the first live reports from a devastating tsunami in the Indian Ocean. However, even before its historical relevance became superseded by the natural disaster, the list already presented a very peculiar survey of television. After all, no major events or catastrophes from the previous year were included in its inventory of captivating spectacles - not Hurricanes Jeanne or Ivan; not the publicized funeral of Ronald Reagan or the much-discussed re-election of George W. Bush; not the historical Olympic Games in Athens or the self-congratulatory Academy Awards. Not a single important live broadcast was featured in the newspaper's year-end reflection. Instead, the list consisted entirely of much more banal events that somehow attained mythical status in public discourse. These included, among others: Janet Jackson's bared breast, Ashlee Simpson's lip-syncing embarrassment, Jon Stewart's political commentary on CNN's Crossfire, and Scott Peterson's cold response to his death penalty sentence.

This strange selection, which emerged amidst wider coverage of feel-good holiday stories and year-end recaps, is by no means an accurate representation of national political values. Nor do I think that its contents can simply be ascribed to journalistic contempt for television. After all, many of the selected televised moments did receive a frenzy of public attention, and were widely circulated or discussed by multiple media. Instead of dismissing these moments as historically irrelevant products of cultural consumption, I argue that they expose the significant role of interruption in establishing and maintaining the effect of television "liveness." The attraction of television liveness, as an ideological (or simulated?) media construction, depends precisely on such brief, unexpected ruptures in

\footnotetext{
Alla Gadassik is currently pursuing her Ph.D. in Screen Cultures at Northwestern University in Chicago. She is interested in the encounters between bodies and technologies in early cinema and new media and her primary research considers filmmaking and animation as technologically mediated kinetic performances. She is excited to participate in this interdisciplinary issue, which bridges media studies and performance studies. In addition to pursuing an academic career, Alla also makes digital animation films. She can be reached at gadassik@u.northwestern.edu.
} 
television's controlled daily flow. In particular, these moments, which elicit fascination among media commentators and viewers, are predominantly constructed around representations of affective corporeal disruptions - bodies out of control, often caught by cameras that are searching for something else.

The interplay of continuity and interruption is a distinguishing, though not technologically determined, televisual mode. The appeal of television liveness (its appeal to and for viewers) is the possibility that anything could happen, that real events or accidents could break through the carefully managed stream of information. Even when television is no longer broadcasting "live," it relies on this promise (it draws on it and mythologizes it) for its claims of accessing the real. At the center of this promise is the televised unruly body, composed for performance but capable of disruption. These are exactly the type of corporeal disruptions that are captured in the New York Times list: Janet Jackson's technological "wardrobe malfunction," during which the celebrity's body becomes uncontained and uncontainable; Ashlee Simpson's awkward flailing dance, which the singer performs upon realizing that she is caught lip-syncing; Jon Stewart's frustrated critique of Crossfire theatrics and his refusal to produce jokes on the show. ${ }^{3}$ Although these examples are drawn from live broadcasts, they reflect a model of affective disruption that extends to a much broader range of television programming. I will return to them throughout the article, to analyze what they reveal about the role of (failed) performance in generating effects of presence and authenticity. ${ }^{4}$

Our experience of television liveness is linked to our encounter with "unscripted" affective moments, when words fail and something else breaks through: gasps, pauses, tears, silences, aggressive eruptions, etc. Television forms reluctant alliances with such "authentic" somatic acts; they can captivate viewers, but they can also become difficult to manage and contain. This affective relationship between media flow and corporeal interruption engages a dynamic of televisual liveness that is distinct from its traditional usage in theatre or performance studies, and yet also relies on performance in ways often ignored by media studies scholars. As this essay will show, this complex dynamic of mediated liveness is supported by media discourse, television's positioning of the spectator, and audience reception. Together, these different aspects construct a unique model of authentic live performance in a medium that no longer promises unmediated temporal access to real events.

\section{Back to You, Live(ness)}

Historically, television was seen as a "live" technology, due to its original model of simultaneous video recording and transmission. ${ }^{5}$ While very few programs are still recorded and broadcast in real time, the cultural and economic excitement generated by early live television continues to pervade many accounts of the medium. Thus, Robert Stam writes that, "although live transmissions form but a 
tiny proportion of programming, that tiny portion sets the tone for all of television." James Friedman goes so far as to suggest that television production rests on a "continuum of liveness," and that this continuum is a helpful aid in analyzing the "murky space between reality and representation" on television. ${ }^{6}$ Despite John Caldwell's critique of the model of liveness, scholars continue to insist on the importance of this concept for television and media studies. ${ }^{?}$

In her oft-cited analysis, Jane Feuer argues that television liveness is not an essential technological quality of the medium. Rather, "liveness" is an ideological framework within which most television programming continues to operate. It is a model of how television continually presents itself to viewers, and "positions the spectator into its 'imaginary' of presence and immediacy." ${ }^{8}$ Feuer argues that this self-referential discourse of liveness allows television programming to maintain the effect of continuity among various disparate segments. For example, programs like early morning shows or news broadcasts include numerous segments that were filmed in separate locations and at different times, but they include direct address in the form of a host or an anchor to tie together the different episodes into the illusion of a single spatial and temporal event. Similarly, Jerome Bourdon argues that all television content "remains deeply influenced by the possibility of live broadcasting." Bourdon maintains that, despite a move away from simultaneous broadcasting, all television content is infused with appeals to presence and immediacy. This effect is maintained primarily through a variety of television production methods and aesthetic choices. These choices include, among others, the prevalence of direct address in images or voice-overs; the pervasive use of the close-up to suggest intimacy and immediacy; and the marketing of the program release schedule as a real time event that imposes itself on the spectator's personal daily schedule.

The elusive construct of "liveness" is often accompanied by a wide array of other concepts: presence, immediacy, intimacy, and reality (to name the most common). Jane Feuer includes these terms in her discussion of television rhetoric, and argues that they represent a connotative slippage from television's early technological potential for instantaneous transmission. Phillip Auslander traces the ideology of liveness even further in time, by examining television's appropriation of theatrical models. Early television shows were aesthetically modeled on live theatre, and were marketed as theatrical performances in real time. Thus, television offered a chance to be present somewhere else temporally, if not spatially. ${ }^{10}$ Auslander argues that spectators" experience of "live" presence and immediacy (im-mediacy as the lack of mediation) emerge from this relationship between television and traditional performance.

While Auslander convincingly explores the unstable boundaries between television and theatre, his focus on the performing arts overlooks another aspect of television history. Television may have borrowed from theatrical and cinematic 
traditions for its aesthetic choices, but it also built on existing communication technologies for its political values and claims to truth. The already-established networks of telegraph and radio transmission had an important impact on commercial television development. For Auslander, early television drew its claims to "liveness" from the theatre, constructing an illusion of co-presence and intimacy among different spectators. This construction was based on myths of the theatre as a non-mediated space, which envelops the spectators into a single live event. ${ }^{11}$ However, I argue that the additional influence of wireless technology contributes further qualities to television's "liveness." Earlier transmission models like the telegraph and the radio were adapted and ideologically circulated as technologies that conveyed authentic and important information across broad (already mediated) spaces and times. ${ }^{12}$ This information was embedded within a viewer's daily life and domestic space, and, more importantly, it was often factual (relaying facts about current personal or social events). Thus, the ideology of liveness was invested as much (if not more) in the authenticity of the information, as it was in the spatial or temporal delivery of the event. The construct of wireless liveness became connected to the idea that something very significant could puncture the daily flow of life and offer a glimpse of something real over great spatial and technological mediations.

Like the telegraph and the radio, early television was used to transmit factual content and to deliver information about ongoing events. Therefore, the promise of television liveness is also a promise of direct access to something "real"- even (or rather especially) if this access is made possible across a distance in space. Like the radio and the telephone, television was a medium brought into the home, into daily routine, and into a post-war suburban culture that worked to reconstruct its national identity and models of citizenship. Thus, the myth of liveness was related not only to the methods of program delivery, but also to ideologies of authenticity and significance of the delivered content. The content in the programs seems "immediate" insofar as real facts or elements are able to come through the apparatus. And the medium has the effect of "intimacy" insofar as it makes people and places known to the viewer. ${ }^{13}$ The entire constellation of terms (presence, immediacy, intimacy) reflects an amalgamation of various effects that converge to produce this construct of televisual liveness. Whereas Auslander astutely critiques a model of liveness based on spatial or temporal contexts (when and where a text is delivered), I would argue that television offers an additional layer of liveness that is ideologically constructed around reality punctuating a mediated flow (arriving despite mediation), rather than governing the entire framework of programming. Even in light of its clear technological mediation, television promotes the expectation that "liveness" still underlies its general programming framework, or what media scholars call its "supertext." The viewer is promised that visual and auditory access will be granted to real events that occur elsewhere. Even when one is not watching "reality" shows or live broadcasts, there is a chance that one will be able to glimpse a real moment, 
or that the programming may be interrupted for a significant event. There is a sense that a viewer will be interrupted from absorption or distraction, in order to be "put in touch" with life elsewhere Here, the interrupting body becomes a key site for signifying and authenticating the emergence of liveness.

\section{From Flow to Disruption}

Televisual liveness is mythologized in the 1976 film Network, which offers a critical portrayal of television as late-capitalism's medium par excellence. ${ }^{14}$ The film's “inciting incident" revolves around an affective outburst during a routine live news flow. Howard Beale, an anchor whose personal troubles lead to his dismissal from his job, breaks down during the transmission and promises to commit suicide in the following broadcast. To the producers' surprise, the struggling network receives a major boost in ratings, as viewers tune in the following night to watch the live event. Instead of apologizing for his behavior, Beale proceeds to curse on-air, which improves the ratings yet again. The network tentatively allows Beale free rein in subsequent broadcasts, whereupon his angry emotional outbursts fulfill the fantasy of televisual effectiveness - he gets viewers to join him in actively expressing their own outrage, even launching a nationwide political campaign.

Paddy Chayefky's award-winning screenplay is often surreal and exaggerated in tone, yet its account of television's dependence on the spectacle of the real is somewhat prophetic of contemporary developments in "reality television" and the later commentaries of media theorists such as Slavoj Žižek and Jean Baudrillard. Above all, the film explores the importance of unruly bodies to the ideology of television "liveness," as well as television's uneasy attempt to control and harness affective interruptions within its otherwise rigid structure.

Mary Ann Doane argues that the complex relationship between the controlled flow of network television and the unexpected interruptions of media events is precisely what characterizes the distinct appeal of television liveness. In other words, in order to support its privileged position in relationship to the "real," television depends on moments that interrupt the regular flow of programming to offer viewers a glimpse of uncontrolled events. Doane's argument is centered on moments of extreme cultural significance and social consequence - the crises and catastrophes covered by television. She argues that "the catastrophe is crucial to television," precisely because it operates as a denial of controlled flow and "corroborates television's access to the momentary, the discontinuous, the real." Whereas Jane Feuer argues that television liveness produces an effect of continuous information that Raymond Williams famously described as "flow," Doane maintains that television is most live, most "televisual," precisely when it suddenly becomes discontinuous. ${ }^{15}$ Doane connects these live discontinuities to major breakdowns of bodies and technologies: economic crises, tragic accidents, natural disasters, and human casualties. 
While Doane's analysis is focused on major interruptions in the television schedule, I argue that interruption is also embedded within everyday television flow. The dialectical movement of control and disruption is not only significant within the larger network of television events but is also a part of what Bourdon calls the common "indices" of television liveness. ${ }^{16}$ Doane's arguments about catastrophe as a momentary breakdown of bodies and technologies can be applied to the internal workings of many models of live television broadcasting: news, sports events, and reality television. It can even be applied to shows not usually broadcast as live events but as part of more mundane daily television programming: ${ }^{17}$ studio shows and sitcoms, talk and game shows, and melodramas. These genres' constructions of televisual liveness largely rely on displays of bodies in action, bodies disrupted, or bodies in disarray.

The body's revelatory potential as a site of access to some sort of underlying real truth or authenticity is deeply embedded in a number of dominant analytical traditions. Psychoanalysis, for instance, relies on the corporeal symptom for its entry into the human psyche. In fact, Williams's concept of television flow suggests a link between media analysis and the psychoanalytic framework of the unconscious. It was Freud, after all, who used metaphors of rivers, currents, and flows to characterize the complex network of forces that converge beneath the seemingly unified stream of consciousness. Just as television liveness, or "reality," is marked by punctures in a controlled media flow, the analyst's access to the unconscious emerges during breaks in the patient's memory and body. Even beyond the original focus on the somatic symptom, psychoanalytic interpretation relies on interruptions in an otherwise continuous flow of speech and recollection. These momentary disturbances, gaps, or pauses are thought to disclose some sort of psychic truths. As in psychoanalysis, the televisual body performs its moments of authenticity through interruptions of narrative and behavioral flow.

A similar framework and vocabulary can be found in contemporary scientific research on human deception. For example, recent developments in lie detection focus on the body's role in providing access to truth about a person's "real" state or intentions. Nonverbal emotion detectors - one of the largest-growing areas in security and law enforcement - are designed to search for tiny disturbances in a person's controlled facial expression. ${ }^{18}$ The theory behind the developing technology is that human beings cannot consciously control the micro-behaviors of their nervous systems and bodies. The body "betrays" the lie by betraying the liar. The research community's widely used term for this occurrence is "leakage," which likens somatic cues to truth that leaks through cracks on a composed corporeal surface.

Within the tradition of performance art — which often resides within the liminal space between the theatrical and everyday reality - the body's transition between continuity and interruption is a significant marker of meaning and authenticity. In his discussion of avant-garde performance pieces, Colin Counsell argues that " $[\mathrm{t}] \mathrm{he}$ 
human body is not usually disruptive, far from it, for most often the body is heavily incultured," yet it nevertheless retains "potential to explode given meanings." Although the avant garde's preoccupation with the body can be traced to the turn of the twentieth century, the emergence of corporeal performance art in America is closely linked to the 1950 's - the decade when television had come to dominate the American household, and mediatization of the "real" penetrated private cultural spheres. Many performance artists thus became concerned with creating a space in which the body was encouraged to encounter its real limits, address its materiality and mortality, or affect audience participants by transgressing acceptable ideological flows. This transgression would often occur when the performance artist would lose control of his or her body - an unexpected confrontation, a loss of consciousness, an eruption of fluids (tears, blood, vomit, etc.) - the latter becoming the widely known and parodied "staple" of performance of performance. "Harrowing as they are," argues Counsell, "such acts are emphatically real, of the here and now." 19 This model of post-war body performance art, which works through a dynamic relationship between the composed "performative" and the disruptive "authentic" (or the "mediated" and the "real"), is closer to what I consider the model of televisual liveness than the traditional theatrical events placed at the core of Auslander's argument. In performance art, as Counsell notes, the disruption of the flowing act is as important as the smooth and unmediated flow of the event itself. In its construction of liveness, of the here and now, television also combines the theatrical with the unexpected confrontation of the real. Although technological breakdowns can cause unplanned interruptions, the subversive potential of live television is most strongly linked to the unruliness of the human body. Facial expressions, body language, and tone of voice can mark an unmediated moment that found its way past the controlled mechanism of the production process. Cecelia Tichi argues that "no matter how carefully composed or controlled, there remain aspects of individuals' self-presentation that are thought to divulge to the viewing eye information otherwise censored by managers, consultants, editors, and other television workers. " ${ }^{20}$ The instant when a television performer becomes most "live" or "real" is the instant when the stream of words or the composure of the face breaks down, enters into a state of collapse, becomes "beside itself."

\section{Getting the Money Shot}

Joe Biden's emotional performance during the 2008 U.S. Vice Presidential debate is a testament to the political potential of the affective televisual interruption. Not a large outburst, Biden's teary-eyed moment was not directly related to the political issues discussed during the debate. In fact, the Vice Presidential candidate's brief emotional recollection went almost entirely unreported in political commentaries that followed the broadcast. However, this minor interruption generated a strong response from viewers at home and sparked discussions on online 
sites and blogs. Clips of Biden's reaction became the most widely posted and viewed footage from that particular debate. From an entire segment of television entirely captured and broadcast in real time, Biden's barely perceptible loss of composure was singled out as the emblematic moment of something significant and "real."

At that moment in the debate, Biden discusses the loss of his wife and daughter, and the difficulties he encountered as a single dad. The memories are tragic, but Biden delivers them with a kind of proud, dignified pathos. The emotional interruption occurs when Biden addresses - subtly - the gendered roles set up in the media between Palin's record of caring parenting and his own "dry" decades of service as a politician: “The notion that because I'm a man I don't know what it's like to raise two kids alone ... I know what it's like." During this sentence, Biden "chokes up" and begins visibly to struggle to continue. He grips the podium, licks his lips, and tries to retain control, before hurriedly finishing the sentence. Since the interruption seemed so unwanted, and since Biden refused to dwell on this difficult moment, viewers characterized it as an unscripted, or intimate, moment.

The brief crack in Biden's stoicism becomes more significant when it is contrasted with Republican opponent Sarah Palin's stuttering response. Unwilling or unable to acknowledge Biden's emotional recollection, Palin's voice awkwardly wavers before she steels her face into a congenial smile and repeats the same scripted phrases she delivered in preceding questions. In subsequent online discussions of this relatively unremarkable debate, viewer sympathy with Biden's brief loss of words was rivaled only by criticism of Palin's mechanical (or "lifeless") response. Her inability to break with her political rhetoric failed to live up to her image as a caring "soccer mom." 21

The minor and almost banal nature of this example betrays the significance of such moments for television's capacity to project liveness and elicit viewer empathy. The televised debate directly addresses viewers as active citizens, and asks them to make judgments about the candidates. On the surface, the debate presents a flow of information about the candidates' policies and parties. However, the most important aspect of the debate is not a presentation of the platforms or arguments, even though they make up the majority of the surface content. Rather, the debate offers a chance for viewers to watch candidates address allegedly unexpected questions or situations and react to challenges brought forth by the opponent. In this regard, a seamless projection of confidence and authority can be either supported or betrayed by the candidate's accidental physical response to pressure. As Tichi notes in her analysis of television close-ups and videoportraits:

[T] he accidental is of paramount importance. It is the source of real knowledge on the viewer's part. It is the crack through which the essence of the individual or his or her type can be apprehended. In the videoportrait, the conceptual presentation 
of self is understood to be a mere mask or facade, a front behind which the real self is concealed. . . . It is the accidental disclosure of truth that the viewer must watch for vigilantly. ${ }^{22}$

One political commentator, who followed Biden on the campaign trail, writes with dismay that the verbose and experienced politician has a knack for blurting out strange asides and gesticulating wildly. Yet this precise quality has made Biden a popular and successful television guest for decades. ${ }^{23}$ His strange combination of reserved, dry rhetoric and periodic outbursts of emotion has been characterized as "a fascinating Off Broadway spectacle [in its] own right." ${ }^{24}$ Although Biden was clearly overshadowed by Palin in media personality coverage, his "accidental disclosure" during the debate became the more memorable highlight of the event.

Television's claims to immediacy and intimacy largely revolve around the figure of the performer or personality (newscaster, politician, show guest, etc.). The mode of direct address so often cited in relation to television liveness emanates from the host or announcer. As noted earlier, the medium also makes frequent use of guiding voice-overs and close-ups, in order to provide viewers with a stable mediator between various segments. However, in addition to establishing a sense of continuity, the television performer's body can become a site of authentication for the genuineness of the content on the screen. Whereas fictional programming depends on seamless, believable acting, most television depends on a believable absence of artifice. Paddy Scannel calls television sincerity a "performative paradox" because it implies a lack of performance. ${ }^{25}$ To this end, viewers look to the performer's behavior for a chance to discern real emotions or catch insincerity. Since all television productions involve various degrees of mediation and staging, a sense of liveness can only be achieved if there is a possibility for something real or unmediated to break through the current of program events. The effect of immediacy that accompanies such moments is extended to the show as a whole.

Importantly, the affective potential of these corporeal interruptions depends on their rarity and irregularity. Programs that consist almost entirely of improvisations and disruptions tend to become incomprehensible; nor do most viewers care to watch a chaotic, fragmented show with poor production content for a prolonged period of time. ${ }^{26}$ The confluence of too many disruptions and irregularities strips the content of any contextual significance or meaning. The promise of live television is most attractive precisely when it offers a seamless and managed flow that nonetheless has the potential to collapse or be subverted in front of the viewers' eyes.

The more obvious examples of live broadcasting, such as news and sports programs, consist of relatively rigid structures that incorporate displays of bodies in disarray. In the news, these displays confront illness and death, whereas in sports they feature collision, collapse, trauma, and physical strain. Both news and sports also feature television personalities whose performances become important 
markers of liveness. ${ }^{27}$ Viewers can empathize with an anchor's emotional reaction to a particularly significant event, or they can get a kind of subversive pleasure from witnessing an on-air slip or outburst. ${ }^{28}$

However, the possibility for authentic reactions is embedded within a much wider range of television genres, including many examples of what Frances Bonner terms "ordinary television." For example, connections between television liveness and disruptive bodies can be found in discussions of talk shows and reality television shows. Not surprisingly, these genres' excessive physical displayswhether emotional or physical - are likened to a kind of televisual pornography of liveness. Laura Grindstaff's fascinating ethnography of talk shows uses the pornographic connotation of the term "money shot" for television's exhibition of "real" human reactions. Grindstaff argues that the structure of the talk show revolves entirely around such "concrete, physical evidence of real, raw emotion." Guests on the show are often "fluffed"-encouraged to release their emotions in front of the cameras at pivotal points in the program. The show's promise of authenticity rests on these raw reactions, which turn "ordinary guests" into "real people." ${ }^{29}$ If the money shot appears to be too big, outlandish, theatrical, or conveniently placed in the show's timeline, then it begins to seem exaggerated and inauthentic. Although the expectations for this genre allow for a greater degree of theatricality, reactions that seem more subdued and "authentic" are still privileged. Still, successful talk shows depend on spontaneous and uncontrolled reactions of real guests, even if the circumstances of these reactions have been staged to various degrees.

Leon Hunt also uses the metaphor of the money shot in his discussion of professional wrestling. ${ }^{30} \mathrm{He}$ argues that spectators are fully aware of the theatrical nature of the events, but they nonetheless appreciate the real risks undertaken in wrestling stunts. Corporeal damage and self-endangerment become markers of authenticity among the staged events. The fights that become most cited and mythologized are not only the ones that stage incredible moves and twists, but also the ones where damage to a wrestler's body interrupted the planned and expected sequence of events.

Audience research on structured reality television shows like Big Brother confirms that viewers are aware of the staged circumstances of these programs as well. Annette Hill's ethnographic study of reality television audiences shows that viewers remain attentive to moments when the performances break down, allowing the cameras a glimpse of a more authentic reaction. Hill argues that viewers enjoy negotiating this continuum between performance and authenticity. ${ }^{31}$ Although Hill's project does not address common cues associated with authenticity, I argue that viewers watch for moments when participants' composure breaks down, when their gestures or interviews betray their emotional states. As in the case of daytime talk shows, outbursts that seem too premeditated or overdetermined by the producers 
begin to appear staged and forced. Instead, primetime reality television producers encourage contestants to drop their inhibitions and lose control of their behavior. To this end, contestants are often submitted to extreme physical exhaustion or supplied with large quantities of alcohol — both tactics aimed at the body as a site of potential chaos and disruption. ${ }^{32}$

Television liveness often relies on the unruly body - whether it is the body of the performer and recorder, or the "real" body (politician, guest, contestant, athlete etc.) caught on tape. Many extra visual effects in television broadcasts, from instant replays in sports events to bumpers and teasers for reality shows, are generated around moments of collision, trauma, and emotional outburst. These moments often spill outside the already-fluid boundaries of the television text, as they become uploaded and circulated by viewers.

\section{(Not Quite) Glued to Their Seats}

The affected television viewer is one who is engaged and touched by the "feeling" medium. The traditional television comedy and talk show both inscribe interruptive audience reactions into their texts, so that viewers at home can hear hoots, bursts of laughter, squeals, and other testaments of the shows' emotional authenticity. The studio viewer transitions from a state of passive observation to one of spontaneous vocal expression, and such transitions are embedded in the shows' visuals or sound. Even if these reactions are prompted by the producers (or added in post-production), for the viewer at home the studio audience nonetheless serves the role of witness to the events on the stage. In sports events, the commentator and the live spectators also serve this role, which Rick Altman terms the "internal audience. ${ }^{\prime 3}$ The internal audience cues the television viewer into the presence of another person who is physically or vocally moved by something important.

Occasionally, studio audience members can become absorbed in the physical altercations between show guests and initiate their own spontaneous conflicts. Laura Grindstaff writes that talk show raucousness onstage can be "reproduced at the level of the studio audience and may even involve physical as well as emotive expressiveness. ${ }^{{ }^{3} 34}$ She notes incidences of audience members fighting with one another, although these moments were edited out of the shows she surveyed. Certainly, The Jerry Springer Show did not discourage occasional audience fights in earlier seasons until threats from regulators and private lawsuits forced producers to contain altercations. ${ }^{35}$

A rare exhibit of such an audience interruption did occur on one particularly absurd episode of Okna ("Windows")—a Russian talk show that looks similar to Jerry Springer, but is more evidently staged. The show features fights between outlandish guests on almost every episode, including one segment that involved a fight with planted audience members. During this segment, the show's host was unable to stay out of the way; as the guests got out of control and demolished the 
sets, the host was badly punched and had to be escorted offstage by security ${ }^{36}$ Although I doubt that the host's bloody nose was faked, the show definitely set up and took advantage of the theatrics of the situation. After all, the incident fit into television's long tradition of imagining and mythologizing the true believer-an uncontrollable viewer fully immersed in the media stream. ${ }^{37}$ If television structures modes of liveness around interrupted bodies on the screen, then the affected body of the spectator also becomes implicated in an interplay of attentive flow and affective disruptive moments. In the case of the show Okna, this involves the studio spectator who is so immersed in the show's events that he is unable to remain calm, composed, and passively entertained by the experience.

However exaggerated the myth of the disruptive viewer may be, it nonetheless reflects the model of live television spectatorship. The affected television viewer is one whose routine has been interrupted by the live event, and whose attention has been captured by the images on the screen. The viewer at home (and away from the site of production, where disruptions can become too damaging) is encouraged to erupt with laughter, break into tears, or gasp with surprise. If the viewer is casually chatting with a friend, the two will fall silent to stare at the screen. If both are already silent and watching intently, the live television moment might cause them to gape in shock. Although the same rings true for theatre, cinema, and other media, television often encourages these reactions by positioning the viewer as a witness of real, unexpected events. As such, textual interruptions are an integral part of television's appeal to and for its audience. The successful moment of television liveness is one that punctures the viewer's suspended disbelief and forces her into one of unwilling belief: "I can't believe this is happening." Or "I can't believe that just happened." But one does believe. ${ }^{38}$ Television viewers are encouraged to harness the intensity of the affective experience toward conscious decisions. They will probably never rush the stage to attack the host. They might, however, punctuate their daily flow to make a call or a purchase. The attractions of live television moments go beyond entertaining the viewer and offering fodder for gossip at the proverbial water cooler. Rather, within the important business model of the medium, these affective experiences of liveness are channelled into subsequent behaviors and actions that hold economic and political relevance. For instance, in terms of the examples already discussed, the disruptions on screen are considered in conscious political judgments and consumer decisions.

\section{The Real and the Obscene}

Live television disruptions are frequently discussed, archived, and circulated in media commentary forums and online video sharing sites. Within hours of a particular noted televised event, the corporeal interruptions are singled out, picked up, and distributed by television viewers and commentators. As online media build their own discourse around (and about) television content, it is clear that affective 
bodily disruptions become clearly marked as somehow important or privileged within the broader television flow. Televised tears, screams, and falls are re-played, slowed down and narrated on sites like "YouTube," not unlike the instant replays of sports commentaries.

An online encounter with these moments after they are first streamed on television is no longer a singular affective encounter. Instead, the online circulation allows viewers to corroborate the importance of these moments within a broader television viewing community. Viewers also debate the authenticity and significance of these moments. Were those tears fake or real? The impact of a particular clip is discussed in the comments, with special attention paid to the interplay of composure and disruption. Entire genres of online video clips have amalgamated around similar moments of bodily interruption: falls, trips, anger fits, dangerous tricks, and so forth. Importantly, the ubiquitous repetition and redistribution of live television breakdowns have led to new public relations and marketing strategies that apparently stage and act out these interruptions on purpose, in hopes of gaining subsequent media attention. For instance, Joaquin Phoenix's seemingly drugged and incomprehensive mumbling on David Letterman's late night show has occasionally been attributed to a carefully executed publicity ploy. ${ }^{39}$ The circulation and recommodification of such strange and disruptive moments have led to an even more complex relationship between performance and supposed "authenticity" on television. The full implications of such a growing online database are outside the scope of this essay; they demand much further research from media and performance studies scholars. Nonetheless, the popularity and proliferation of such moments support this paper's central argument about the significance of the unruly body to the constructions of mediated liveness in televised events.

Occasionally, television liveness becomes too "live" for its own good, as its unruly bodies threaten to escape from the spectacular and make a spectacle out of television itself. A news anchor stammers, curses, and slams his desk in frustration. A game show host throws up on the air. A reporter, cued live on the scene, is too busy yelling at a nearby bystander. There is an entire online genre of clips that capture and edit together such interruptions in news broadcasts and other television programs. Certain themes recur among these clips: news anchors erupting in laughter or angry frustration; hosts accidentally blurting out Freudian slips; television personalities cursing right before or after they're cued to air; onlocation reporters irritated with drunks, streakers, protesters, children, and other "undesirable" living presences. In these moments the "real" intrudes too far into television - the fragile threshold between the mesmerizing and the irritatingly chaotic. Such moments are an uncomfortable zone for the television industry. On one hand, they support televisual liveness and television's claims to the real. They are often noticed and circulated in print and online (e.g. the New York Times list from the beginning of this article). The scandalous blunders of live television add 
authenticity and weight to the broader range of affective disruptions on television, which I have explored throughout this paper. But on the other hand, these blunders can subvert television's authority and meaning-making. After all, since these interruptions depend on a temporary loss of control and continuity, they can also symbolize a temporary breakdown of television itself.

Television performances become most "live" when they break down. It is easiest to judge the authenticity of something when it becomes clearly inauthentic, such as when Ashlee Simpson's performance is exposed as fake due to an error. Similarly, Grindstaff notes that the nightmare intrusion of the "real" into talk shows are the moments when guests freeze up with emotion, cannot talk, or storm off the set. ${ }^{40}$ On reality shows, bodies can break down to the point where they can no longer compete in the circumscribed world of the program: a Survivor contestant is evacuated due to skin burns; a Project Runway contestant leaves with a swollen face and a dangerous infection; Cheaters host Joey Greco gets stabbed by a male guest, suspected to be unfaithful, when he is confronted by his wife on this reality television show. In subsequent post-production and editing, the makers of these shows reinscribe the disruptive events into the narrative and fold them back into the flow of the program. These events may even become marketing ploys, as episode trailers and teasers promise shocking live moments to the viewers. Nonetheless, the extreme cases of corporeal risk (death, serious injury) can also threaten the shows' very existence, in terms of legal implications and performance potential, as guests or hosts become compromised by unexpected crises. ${ }^{41}$

Television programs' credibility and supposed authenticity can be compromised in more subtle ways as well. On the aforementioned 2004 episode of the CNN show Crossfire, a famous breakdown occurs when Jon Stewart's disruption of the standard program routine exposes the entire show as a theatrical farce. The segment is fascinating, because Stewart (the "comedian") refuses to laugh in the course of his political appeal, whereas the two hosts (the "tough political pundits") suddenly struggle to maintain rigid smiles and jokes. The comedian's appearance may have boosted temporary ratings, but it helped put the proverbial nail in the coffin of an already struggling program. Just as Stewart's outburst threatened the ethos of CNN, Janet Jackson's exposed anatomy threatened Superbowl broadcasters with government fines and advertising losses.

When live corporeal interruptions become dangerous for television, extreme measures are taken to ensure that it occurs according to plan, that it remains under control. On talk shows, audiences are prepped and manipulated as often as the guests. ${ }^{42}$ Risk assessments are filled out and security personnel are hired. Seven second delays are inserted as an extra precaution. Yet, television still needs affective interruptions for life support, or rather, for liveness support. And so it maintains an uneasy relationship with its unstable affective bodies.

Perhaps this relationship reflects a continual drive to reinscribe the real into a 
circuit dominated by simulation. If Baudrillard is right in characterizing modern communication as obscene ecstasy and pornography, then perhaps the television "money shot" is the main currency of simulated intimacy and immediacy. ${ }^{43}$ Perhaps corporeal interruptions also help people distinguish between performance and reality in human behavior - the blurring of the theatrical and the everyday that was the focus of sociologist Erwin Goffman's work. In this case, the appeal of disruption is inseparable from social expectations and codes associated with various television texts and genres. Media theorists often quote Walter Benjamin's famous arguments about 'the desire of contemporary masses to bring things 'closer' spatially and humanly, which is just as ardent as their bent toward overcoming the uniqueness of every reality by accepting its reproduction." 44 However, although the media viewer may search for intimacy in reproduction, she is reluctant to relinquish the desire for the uniqueness of everyday reality. The ideology of televisual liveness promises to bring things closer and show them in their uniqueness, even when that uniqueness is quickly subsumed into the indiscriminate flow. The viewer is left waiting, watching, vigilant for the eruption that can mark a site of authenticity.

Current television models continue to change and interact with other media forms: the online site Youtube has recently broadcast its first real-time live spectacular, web giant Google is forging partnerships with media content providers, and traditional news broadcasters continue to consolidate their online information flows. Discussions of emerging media distribution forms are already trying to address the concept of internet and mobile liveness. ${ }^{45}$ It will be interesting to see if (and how) the interplay of continuity and interruption will be inscribed in these digital flows, and if this interplay will draw on the affective potential of the disruptive body. In the meantime, the possibility of affective liveness remains one of the continuing appeals of televisual media models, even when those models may no longer be connected to the technology we have historically associated with television.

\section{Notes}

1. The author would like to thank Lynn Spigel for her expertise, support, and thoughtful feedback on earlier drafts of this paper. The author is also grateful to the editors for their invaluable comments and sugestions.

2. Virginia Heffernan, “TV's Best Live Moments,” New York Times, 26 Dec. 2004. 6 May 2010 $<$ http://www.nytimes.com/2004/12/26/arts/television/26heff.html>.

3. On the other hand, there is Scott Peterson's expressionless face — his lack of emotional outpouring in light of his death sentence - treated as evidence of abnormality and guilt.

4. Although this article focuses on a select list of examples, the arguments apply to numerous instances of notable and much-discussed media disruptions. Even as this paper article moves to publication, new "live television" scandals are passing through the media circuit: singer Adam Lambert's unpredictable and sexualized behavior during televised performances; actress and talk-show host Whoopi Goldberg's temporary walk-out from The View.

5. For a historical account of the development and demise of live (simultaneous) broadcasting, 
see William Boddy, Fifties Television (Chicago: U of Illinois P: 1992).

6. Quoted in James Freeman, Introduction, Reality Squared: Televisional Discourse on the Reel (Piscataway, NJ: Rutgers U P, 2002) 2, 143, 5.

7. John Caldwell's critique in Televisuality: Style, Crisis and Authority in American Television (New Brunswick, NJ: Rutgers U P, 1995), is addressed and contested by Jerome Bourdon, "Live Television is Still Alive: On Television as an unfulfilled Promise," The Television Studies Reader, ed. Robert Allen and Annette Hill (London: Routledge, 2004) 182-195, and Rhona Berenstein, "Acting Live: TV Performance, Intimacy, and Immediacy (1945-1955)," Reality Squared: Televisual Discourse on the Real, 25-49. Arild Fetveit in "Reality TV in the Digital Era: A Paradox in Visual Culture," Reality Squared 119-137, also discusses the rise of reality television genres within an era dominated by the kind of technical effects and manipulations that Caldwell associated with television aesthetics.

8. Jane Feuer "Concept of Live TV: Ontology as Ideology," Regarding Television: Critical Approaches, An Anthology, ed. E. Ann Kaplan (Bethesda, MD: U Publications of America, 1983) 1222. Here, Feuer draws on Stephen Heath and Gillian Skirrow's discussion of television programming in "Television: A World in Action," Screen 18.2 (1977): 7-59.

9. Bourdon 82.

10. Phillip Auslander, Liveness: Performance in a Mediatized Culture (New York: Routledge, 2008) 60 .

11. Auslander 13-22.

12. The telegraph even became central to the emerging movement of spiritualism, which claimed access to the world of other spirits through wireless technology. See Jeffrey Sconce, Haunted Media: Electronic Presence From Telegraphy to Television (Durham: Duke U P, 2000).

13. From the Latin intimare: to make known, announce, impress.

14. Of course, by highlighting the dehumanized profit-driven model of television, the film obscures Hollywood's own complicity in this economy.

15. Mary Ann Doane, "Information, Crisis, Catastrophe," From Old Media to New Media, ed. Wendy Hui Kyong and Thomas W. Keenan (New York: Routledge, 2005) 251-64.

16. Bourdon 182.

17. I am borrowing these from Francis Bonner's discussion of "ordinary" television, Ordinary Television: Analyzing Popular TV (London: Sage, 2003), and Mimi White's proposed forms of more "banal" alternatives to live television broadcasts, "The Attractions of Television: Reconsidering Liveness," MediaSpace: Place, Scale and Culture in a Media Age, ed. Nick Couldry and Arina McCarthy (London: Routledge, 2004) 75-92. See White's essay, in particular, for an additional model of television liveness based on spatial rather than temporal connections to the "real."

18. See Nancy Ross-Flanigan, "Facing the Truth: A New Tool to Analyze Our Expressions," HHMI Bulletin May 2001, 6 May 2010<http://www.hhmi.org/bulletin/may2001/faces/., or the work of Paul Ekman, <http: www.paulekman.com/, developer of the Micro Expression Training Tool. Ekman's work has recently been adapted for the screen in the television show Lie to Me.

19. Colin Counsell, Signs of Performance: An Introduction to Twentieth Century Theatre (New York: Routledge, 1996) 223, 225.

20. Cecilia Tichi, Electronic Hearth (New York: Oxford U P, 1991) 159.

21. Sarah Palin's media image relied heavily on her physical appearance and behavior-a reflection of our political and cultural gender divisions that was not entirely discouraged by her political campaign. This body image includes not only Palin's history as a pageant contestant, but also her role as a mother of several children (including a child with Down's Syndrome), her expressive gestures and winks, and her colloquial verbal pronunciations. For one example of media commentary on this aspect of the Vice-Presidential debate, see Mike Madden, "Sarah Palin Exceeds Expectations-And Still Loses," Salon 30 October 2008, 6 May $2010<$ http://www.salon.com/news/feature/2008/10/03/ palin_biden/>. Ardent Palin supporter Matthew Continetti supports this image of Palin as much as he critiques her treatment in the media. See The Persecution of Sarah Palin (New York: Sentinel-Penguin, 2009). Sarah Palin herself struggles with her media image in her recent book Going Rogue (New York: Harper Collins, 2009) and then goes on to brag about her performances on television and her love as both a mother and a caring woman.

22. Tichi 162 . 
23. Brian Massumi's application of Deleuzian affect theory to politics includes a similar argument about Ronald Reagan's political persona. See Parables for the Virtual: Movement, Affect, Sensation (Durham: Duke U P, 2002) 40-2.

24. Mark Liebovich, "Meanwhile, the Other No. 2 Keeps on Punching," New York Times 19 Sept. 2008, 6 May $2010<$ http://www.nytimes.com/2008/09/20/us/politics/20biden.html?_r=2\&oref=slogin>.

25. Paddy Scannel, Radio, Television, and Modern Life (Oxford: Blackwell, 1996) 58.

26. One notable exception to this rule is the comedy genre, although most television comedies are still structured around a dominant and continuous narrative flow with only occasional comedic punctuations (often hinging on corporeal disruptions).

27. Both Doane (258) and Bourdon (185) briefly mention that stumbling announcers make the strongest indicators of live television.

28. For a discussion of television news personalities, see Margaret Morse, "News as Performance: The Image as Event," The Television Studies Reader, 209-25. Morse discusses Walter Cronkite's emotional reaction to Kennedy's assassination as a contributing factor to his claims to credibility and sincerity (73).

29. Laura Grindstaff, The Money Shot (Chicago: U of Chicago P, 2002) 116, 72.

30. Leon Hunt, "Helina Cell and Other Stories: Violence, Endangerment, and Authenticity in Professional Wrestling," The Spectacle of the Real: From Hollywood to Reality TV and Beyond, ed. Geoff King (Portland, OR: Intellect Books, 2005) 117-27.

31. Annette Hill, Reality TV: Audiences and Popular Factual Television (London: Routledge, 2005).

32. Occasionally, the authentication of televisual liveness also relies on the camera as an embodied witness to the disruption. Hand held camera footage is often included in reality programs, talk shows, live news coverage, and even (increasingly) television comedy and drama. A camera swerves or frantically racks focus to catch a spontaneous incident. However, these interruptions remain infrequent, or they lose meaning or significance in their eventfulness and the show risks becoming an "amateur" production. In "Caught on Tape: A Legacy of Low-Tech Reality" (The Spectacle of the Real, 82-92), Amy West discusses hand held camera techniques as part of television's legacy of featuring unpremeditated events "caught on tape." Amateur camera movements are used to show "an interconnection of human body and recording device," as the camera operator becomes a live witness to an accident or aberration (87). Lee Rodney's article "Real Time, Catastrophe, Spectacle: Reality as Fantasy in Live Media" (The Spectacle of The Real, 38-45), makes a similar case for disaster news coverage. Rodney argues that shaky hand held footage and off-screen gasps became the most emblematic significations of the reality and significance of September 11 media coverage (39). Margaret Morse also analyzes the political connotations of camera turns and interruptions in her discussion of the Romanian tele-revolution. The experience of watching these technological interruptions is different from the experience of watching television snow or digital distortions.

33. Rick Altman, "Television/Sound," Studies in Entertainment, ed. Tania Modleski (Bloomington: U of Indiana P, 1986) 39-54.

34. Grindstaff 67.

35. Lawrie Mifflin, "Studio to rein in violence on 'Jerry Springer'," New York Times, 26 May 2010, 6 May $2010<$ http://query.nytimes.com/gst/fullpage.html?res=9C03E4D81331F935A15756C0 A96F958260\&sec $=\&$ spon $=\&$ pagewanted $=$ print; $>$.

36. The American equivalent - one that is highly unlikely to occur-would be Jerry Springer getting a bloody nose mid-show.

37. For an interesting cultural analysis of narratives of the immersed or "sucked in" spectator, see Sconce Haunted Media.

38. If the event is expected, one watches with conscious belief or suspended disbelief. If it is too exaggerated or seems fake, one cannot trust the images and can only enjoy the theatrics.

39. Rolling Stone commentator Daniel Kreps, for instance, discussed this appearance as a PR performance in the tradition of the late comedian Andy Kaufman ("Joaquin Phoenix Appears on 'David Letterman,' Kind of," Rolling Stone, 12 February 2009. <http://www.rollingstone.com/rockdaily/index. php/2009/02/12/joaquin-phoenix-appears-on-david-letterman-kind-of $>$ ) An entire separate essay could be written about the long history of corporeal live "scandals" on the David Letterman show-history largely supported by Letterman's own television persona as an unruly host. 
40. Grindstaff 116 .

41. This argument can be extended to the more subtle but nonetheless important instances of television actor illness or pregnancy. Both cases significantly impact the programming of the shows, often changing the story lines and release schedules of the episodes.

42. Alanna Autler, "The carefully-managed audience manipulation that makes 'Jerry Springer,", North by Northwestern, 6 Nov. 2008, 6 May $2010<$ http://www.northbynorthwestern.com/2008/11/13387/ the-carefully-managed-audience-manipulation-that-makes-jerry-springer-so-entertaining/>.

43. Jean Baudrillard, "The Ecstasy of Communication," The Anti-Aesthetic: Essays on Postmodern Culture, trans. John Johnston, ed. H. Foster (Port Townsend: WA Bay P, 1983) 126-34. A "Baudrillardian" reading of liveness also made by Auslander and Fetveit.

44. Walter Benjamin, "The Work of Art in the Age of Mechanical Reproduction," reprinted in Media and Cultural Studies, ed. Douglas Kellner and Meenakshi Gigi (Oxford: Blackwell, 2001) 52.

45. See, for example, Tara McPherson, "Reload: Liveness, Mobility, and the Web," From Old Media to New Media, 119-208, and Michele White, "Television and Internet Differences by Design: Rendering Liveness, Presence, and Lived Space," Convergence 12.3 (2006): 341-55. White discusses the factors of spatial and temporal proximity in her analysis of internet liveness, but does not acknowledge the importance of interruption, as discussed by Doane; performance and authenticity, as discussed by Auslander; or affective engagement, as discussed in this article. 